\title{
Nitretação a plasma da junta soldada do aço inoxidável super duplex SAF 2507
}

\author{
Plasma nitriding of welded joint of the \\ SAF 2507 super duplex stainless \\ steel
}

Ferdinando Marco Rodrigues Borges ${ }^{1}$, Valdemar Silva Leal ${ }^{2}$, Franklyn Erikson da Silva Guimarães ${ }^{1}$, Valtair Antônio Ferraresi ${ }^{3}$, Romulo Ribeiro Magalhães de Sousa ${ }^{1}$

\author{
${ }^{1}$ Programa de Pós Graduação em Ciências dos Materiais, PPGCM, UFPI, CEP: 64049550, Teresina, Piauí, Brasil. \\ ${ }^{2}$ Programa de Pós Graduação em Ciência e Engenharia de Materiais, PPGEM, IFMA, CEP: 65030005, São Luís, Mara- \\ nhão, Brasil. \\ ${ }^{3}$ Faculdade de Engenharia Mecânica da Universidade Federal de Uberlândia, UFU, CEP: 38400902, Uberlândia, Minas \\ Gerais, Brasil. \\ e-mail: ferdinando@ifma.edu.br
}

\section{RESUMO}

Os aços inoxidáveis superduplex (AISD) apresentam em sua microestrutura as fases ferrita e austenita, de modo a conciliar boas propriedades mecânicas e de resistência à corrosão. Estes materiais possuem grande aplicação na indústria de extração de petróleo e na petroquímica. Quando estão sujeitos a estas aplicações, os dutos de AISD sofrem desgastes. Dentre os tipos, pode-se citar o proveniente do atrito de cabos que levam ferramentas para o interior de poços. Levando em consideração a soldagem dos aços superduplex, a suscetibilidade ao desgaste e à corrosão podem aumentar. Valores de energia de soldagem acima de $1,5 \mathrm{KJ} / \mathrm{mm}$ ocasionam o desbalanceamento de fases, prejudicando as propriedades citadas. A ZTA (zona termicamente afetada) da solda destes aços é a região mais suscetível à degradação e fragilização devido ao crescimento do grão ferrítico e possível surgimento de precipitados deletérios. Neste contexto, este trabalho tem como um dos objetivos nitretar a junta soldada do aço SAF 2507 e correlacionar a microestrutura com a dureza superficial. Para alcançar os resultados, amostras de junta soldada foram nitretadas a plasma utilizando as técnicas de nitretação convencional (NC) e em gaiola catódica (NGC) na temperatura de $400{ }^{\circ} \mathrm{C}$. Em decorrência, as amostras nitretadas com o uso da gaiola catódica apresentaram maiores e mais uniformes valores de microdureza.

Palavras-chave: Superduplex, nitretação, microdureza.

\begin{abstract}
Superduplex stainless steels (SDSS) present in their microstructure the ferrite and austenite phases, in order to reconcile good mechanical properties and resistance to corrosion. These materials are widely used in the petroleum extraction and petrochemical industries. When subjected to these applications, the SDSS ducts are worn. Among the types, we can mention the coming from the friction of cables that take tools into the wells. Taking into account the welding of superduplex steels, the susceptibility to wear and corrosion may increase. Solder energy values above $1.5 \mathrm{KJ} / \mathrm{mm}$ cause phase imbalance, damaging the mentioned properties. The HAZ (heat affected zone) of welding of these steels is the region most susceptible to degradation and embrittlement due to the growth of the ferritic grain and possible emergence of deleterious precipitates. In this context, this work has as one of the objectives to nitrate the brazed joint of the SAF 2507 steel and to correlate the microstructure with the surface hardness. To achieve the results, samples of welded joint were nitrided to plasma using conventional $(\mathrm{CN})$ and cathodic cage $(\mathrm{CCN})$ techniques at a temperature of $400{ }^{\circ} \mathrm{C}$. As a result, the nitrided samples with the cathodic cage showed larger and more uniform values of microhardness.
\end{abstract}

Keywords: Superduplex, nitriding, microhardness. 


\section{INTRODUÇÃO}

Os aços superduplex são uma categoria dos inoxidáveis que apresentam fases microestruturais austenítica e ferrítica em proporções aproximadas de $50 \%$ de cada, devido à sua composição química e tratamento térmico. Possuem um alto teor de $\mathrm{Cr}$ e, também, são caracterizados por baixo teor de carbono, menor que $0,03 \% \mathrm{em}$ peso. Contém elementos de liga, como molibdênio, tungstênio, cobre e nitrogênio. Estes aços são chamados de ligas especiais e são usados em locais com atmosferas agressivas que exigem alta resistência à corrosão e ótimas propriedades mecânicas [1, 2].

Uma das principais aplicações destes metais é na indústria de refinamento de petróleo e petroquímica, como: plataformas de petróleo, atividades offshore, exploração de petróleo, sistemas de tubulação, evaporadores, destiladores, tanques de armazenamento, entre outros, onde são necessárias as propriedades acima citadas [3].

Em se tratando de juntas soldadas de aços superduplex, a grande dificuldade é obter quantidades de austenita próximas a $50 \%$ e evitar a formação de fases prejudiciais (deletérias) no resfriamento. As frações volumétricas de austenita inferiores a $25 \%$ são inaceitáveis para a maioria das aplicações industriais. A norma Norsok Standard para inspeção de soldagem em tubulações petrolíferas indica um conteúdo mínimo de austenita de 30\% no passe de acabamento e de raiz, como um valor necessário para aceitar a solda em juntas [4,5]. Para se obter um cordão de solda com as propriedades desejadas, deve-se atentar, principalmente, para o controle do calor de entrada e a composição química da solda, que influencia na microestrutura, propriedades mecânicas e na resistência à corrosão [6,7].

A solda é dividida em três regiões, a saber: zona fundida (ZF), zona termicamente afetada (ZTA) e metal base (MB). Quando houver em uma estrutura metálica regiões de solda, estas são as mais suscetíveis à corrosão e a apresentar uma fratura; e apresentando duas fases, como o superduplex, é preciso atentar-se para o percentual de fases, buscando sempre frações aproximadas. Principalmente na ZTA dos aços superduplex ocorrem as maiores possibilidades de incidências de trincas e ataques corrosivos. Isso ocorre porque esta região é a de maior precipitação de fases deletérias e crescimento de grãos ferríticos decorrentes da tempertatura submetida e da velocidade de resfriamento. A energia de soldagem empregada no processo, o controle de resfriamento e a composição de arame de solda ditam a fração volumétrica de ferrita e austenita. A austenita possui uma maior resistência à corrosão e uma maior ductilidade, enquanto a ferrita possui uma maior dureza, todavia, maior fragilidade.

Os tratamentos superficiais entram no contexto desse trabalho para melhorar a dureza superficial do material, tendo em vista que tubulações utilizadas em perfuração e extração de petróleo sofrem desgastes. Dentre estes, os causados pelo atrito de cabos que levam ferramentas até o fundo de poços com a parede interna do duto. O tipo de tratamento utilizado neste trabalho é a nitretação a plasma. Neste, os átomos de nitrogênio são dissociados, ionizados e transportados a altas velocidades até a superfície do metal. Uma camada característica é produzida através da difusão de nitrogênio na superfície metálica e as propriedades desta camada superficial podem ser modificadas variando-se os parâmetros do processo como temperatura, tempo de tratamento e pressão.

Um dos artifícios utilizados na nitretação por plasma é a gaiola catódica (NGC). Esta técnica consiste em pulverização catódica reativa via plasma convencional, onde as amostras são isoladas eletricamente por estarem sobre um disco cerâmico (alumina) e uma fonte de tensão, contínua ou pulsada, aplica uma diferença de potencial na gaiola, isentando as amostras dos inconvenientes do plasma convencional. Do exposto, este trabalho tem como objetivo investigar a correlação entre a microestrutura e a microdureza do material com e sem nitretação e comparar a dureza superficial obtida através das duas técnicas utilizadas (NC e NGC).

\section{MATERIAIS E MÉTODOS}

O material usado neste trabalho é o aço inoxidável superduplex SAF 2507 com metal de adição de arame ER 2594. As composições químicas nominais são apresentadas na Tabela 1.

Tabela 1: Composição química nominal do aço superduplex SAF 2507 e do metal de adição ER2594 (\% massa).

\begin{tabular}{c|c|c|c|c|c|c|c|c|c|c}
\hline Material & Cr & Mo & Ni & C & N & Mn & Si & P & S & Fe \\
\hline SAF 2507 & 24,92 & 3,77 & 7,05 & 0,014 & 0,261 & 0,76 & 0,39 & 0,022 & 0,001 & Bal. \\
\hline ER 2594 & 24,92 & 3,9 & 9,19 & 0,011 & 0,28 & 0,6 & 0,46 & 0,019 & 0,005 & Bal. \\
\hline
\end{tabular}




\subsection{Procedimento de soldagem}

A soldagem foi realizada através do processo MIG-MAG (Metal inert gas/ Metal active gas) por transferência curto-circuito derivativo STT (Surface Tension Transfer), utilizando como metal de adição o arame ER 2594 e gás de proteção a mistura $\mathrm{Ar}+2 \% \mathrm{O}_{2}$ e $\mathrm{Ar}$ puro como gás de purga na raiz. O cordão de solda foi realizado com auxílio de uma fonte $\mathrm{PW}-455 \mathrm{~m} / \mathrm{STT}$ ligada a um braço robotizado HP-20 para deslocamento automático da tocha de soldagem. O robô possui regulagem de velocidade de avanço, muito importante para o controle das energias de soldagem. A solda foi executada em dois passes, utilizando os seguintes valores de energia: $\mathrm{EJ}=0,654 \mathrm{~kJ} / \mathrm{mm}$ (raiz STT) e EJ = 1,47 kJ/mm (enchimento STT), com variação de corrente entre 80 e 125 A e voltagem entre 14,6 e $21,0 \mathrm{~V}$, a fim de evitar o desequilíbrio de fases, como também evitar o surgimento de precipitados, onde ambos os casos podem fragilizar a junta soldada.

Para realização do trabalho, além das juntas de teste, uma chapa foi soldada ao par, medindo $150 \mathrm{~mm}$ x $150 \mathrm{~mm}$ x $6 \mathrm{~mm}$ com cunha em $\mathrm{V}\left(\alpha=60^{\circ}\right)$, abertura de raiz (d) de $2 \mathrm{~mm}$ e espessura da chapa (t) de $6 \mathrm{~mm}$. As juntas foram dispostas sobre um cobre-junta para possibilitar a integridade da raiz da solda.

Após o procedimento de soldagem foram retiradas amostras na direção transversal, nas dimensões de 20 x 15 × 6 mm; as mesmas foram fresadas para retirada do reforço e planificação da chapa. Posteriormente, as amostras passaram pelo processo de metalografia onde foram lixadas com lixas d'água de granulometria: 200, 320, 400, 600 e 1200 MESH. Logo após, polidas em disco de feltro com pasta diamante (3 $\mu$ m) e fluido lubrificante para limpeza e acabamento até a superfície do metal ficar com aparência espelhada. Após o polimento, antes de cada tratamento de nitretação, as amostras foram limpas em acetona P.A. durante 10 minutos em um equipamento de ultrassom.

\subsection{Processo de nitretação por plasma}

$\mathrm{Na}$ nitretação iônica convencional e em gaiola catódica utilizou-se o mesmo equipamento. A fonte de tensão é contínua e possui voltagem e corrente máximas de $1500 \mathrm{~V}$ e $2 \mathrm{~A}$, respectivamente. A câmara de vácuo é cilíndrica com $30 \mathrm{~cm}$ de diâmetro e $40 \mathrm{~cm}$ de altura, confeccionada de aço inoxidável. O dispositivo chamado gaiola catódica foi confeccionado de folha de aço inoxidável austenítico AISI 304, com 0,8 mm de espessura. A gaiola possui $112 \mathrm{~mm}$ de diâmetro, $25 \mathrm{~mm}$ de altura e furos de $8 \mathrm{~mm}$ de diâmetro uniformemente distribuídos com distância de 9,2 mm entre centros de furos adjacentes. Na nitretação com gaiola catódica, a amostra é colocada sobre um disco isolante de alumina conforme Figura 1. O plasma é formado na gaiola catódica (cátodo) e não diretamente na superfície das amostras (nitretação convencional), que permanecem em potencial flutuante, posicionadas em uma superfície isolante.

Nos dois tipos de nitretação utilizados, inicialmente ocorre a etapa de pré-tratamento (pré-sputtering), consistindo na exposição das amostras e da gaiola catódica à uma atmosfera de composição equilibrada com $50 \% \mathrm{H}_{2}+50 \%$ Ar, na pressão de 1 mbar. O pré-tratamento terá a função de fazer a limpeza do conjunto, ativando a superfície para a interação com o plasma e fazendo a remoção de impurezas que ainda estão remanescentes. No tratamento propriamente dito, as proporções de gases utilizadas na nitretação convencional foram de $80 \% \mathrm{H}_{2}+20 \% \mathrm{~N}_{2}$ e com a gaiola catódica foram utilizadas $80 \% \mathrm{~N}_{2}+20 \% \mathrm{H}_{2}$. Manteve-se os percentuais de gases obtidos por SOUSA, et al. [8], que conseguiram obter camadas mais espessas com essa proporção. A temperatura utilizada nos tratamentos foi de $400^{\circ} \mathrm{C}$. Todas as amostras foram tratadas durante 5 horas na pressão de 3 mbar.

\subsection{Caracterizações}

Para certificação da composição das fases presentes na junta soldada do aço superduplex SAF 2507, submeteu-se à análise por difração de raios X no difratômetro modelo SHIMADZU XRD-6000, com geometria Theta/Theta e com um detector Pixel $1 \mathrm{D}$, radiação monocromática $\mathrm{K} \alpha(\lambda=1,540598 \AA$ ) de tubo de cobre. Os registros foram coletados nas seguintes condições: voltagem de $40 \mathrm{kV}$, corrente $30 \mathrm{~mA}$, no intervalo angular $35-85^{\circ}(2 \theta)$ com um passo de $0,02626^{\circ}(2 \theta)$ e um tempo de contagem de 80,15 s. Para a identificação das fases cristalinas utilizou-se o software HighScore Plus versão 3.0 e a base de dados PDF 2-ICDD.

A microscopia ótica foi utilizada para caracterizar a microestrutura do metal base, das zonas oriundas da soldagem, medidas de espessura de camada e para cálculo de frações volumétricas de ferrrita. As imagens foram capturadas na parte superior e no perfil da solda pelo equipamento da marca Bel Photonics modelo MTM-1A. Todas as amostras utilizadas em microscopia ótica foram atacadas por reagente Behara $(20 \mathrm{~mL}$ de ácido clorídrico, $80 \mathrm{~mL}$ de água destilada e $1 \mathrm{~g}$ de metabissulfito de potássio) para revelar a microestrutura. A ferrita por ser mais reativa que a austenita ao ataque Behara fica em mais baixo relevo, facilitando a diferenciação destas fases. As medidas de espessura de camada e cálculos de frações volumétricas de ferrita foram realizadas com o auxílio do software ImageJ. Nas medidas de espessura de camada foram feitas cinco medi- 
ções ao longo da camada nitretada de onde adveio a média aritmética. No cálculo da fração volumétrica de ferrita adotou-se o aumento de 200X, a imagem foi binarizada e utilizou-se cinco (05) campos por amostra para obtenção dos percentuais.

A técnica de MEV (microscopia eletrônica de varredura) foi utilizada para avaliar qualitativamente a microestrutura da junta soldada na parte superior, a fim de avaliar a granulação da mesma. Utilizou-se o microscópio eletrônico de varredura, modelo Quanta 250 FEG da marca FEI.

Os ensaios de microdureza Vickers foram realizados com um microdurômetro modelo ISH - TDV 1000 A-B da marca INSIZE. Para a microdureza das fases, utilizou-se uma carga de 10gf por 15 segundos. Para as indentações nas regiões da solda com e sem nitretação, utilizou-se uma carga de 50 gf por 15 segundos. O espaçamento entre as medidas foi de 0,2 $\mathrm{mm}$ (recomendado pela Norsok Standard item 4.3.4).

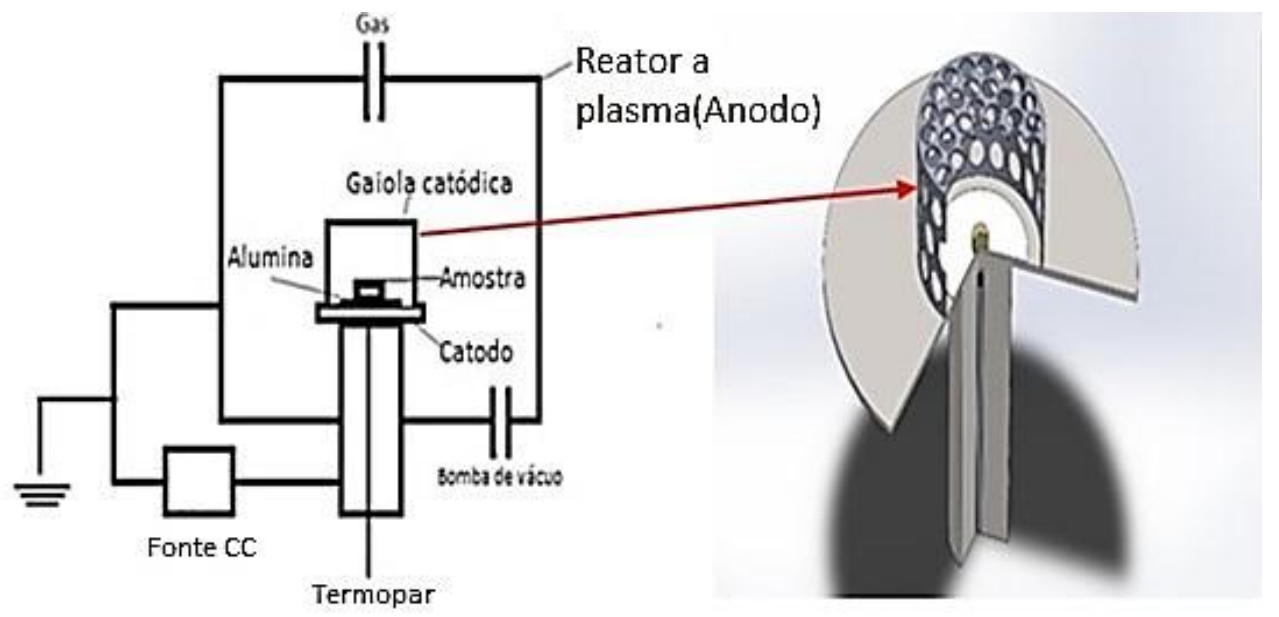

Figura 1: Representação esquemática em corte do artifício da gaiola catódica.

\section{RESULTADOS E DISCUSSÃO}

\subsection{Difração de raio $x$}

O padrão de difração de raios $X$ da junta soldada do aço superduplex (SAF 2507) da amostra nitretada convencionalmente $\left(\mathrm{NC} 400^{\circ} \mathrm{C}\right.$ ) e em gaiola catódica $\left(\mathrm{NGC} 400^{\circ} \mathrm{C}\right.$ ) é exposto na Figura 2. Pode-se verificar, na junta soldada sem nitretação (JS SAF 2507), apenas picos de ferrita e austenita, indicando que a microestrutura é composta somente por essas duas fases.

No difratograma do tratamento a plasma convencional de $400^{\circ} \mathrm{C}\left(\mathrm{NC} 400^{\circ} \mathrm{C}\right)$ é razoável inferir que a camada nitretada formada na superfície era suficientemente fina e com irregularidades o que permitiu a detecção do substrato, além das fases de austenita expandida e ferrita expandida. Três novos picos mais amplos e desviados para ângulos de difração um pouco menores apareceram em $2 \theta=42,66^{\circ}, 2 \theta=49,52$ e $2 \theta=$ $72,84^{\circ}$, identificados como austenita expandida $\left(\mathrm{Fe}-\gamma_{\mathrm{N}}\right)$. Isto indica um aumento nos parâmetros de rede devido à supersaturação de nitrogênio na célula cristalina $\mathrm{CFC}$ da austenita $[1,2,9]$. Além disso, os três picos ferríticos (Fe- $\alpha$ ) localizados em ângulos de $2 \theta$ de $44,48^{\circ}, 64,68^{\circ}$ e $81,82^{\circ}$, tornaram-se um pouco mais alargados e assimétricos, indicando uma contribuição da fase de ferrita expandida $\mathrm{Fe}-\alpha_{\mathrm{N}}$ [2]. Na amostra tratada com gaiola catódica há difrações de planos referentes a fase $\mathrm{Fe}_{3} \mathrm{~N}$. Constata-se nos ângulos $2 \theta=40,88^{\circ}$ e $46,18^{\circ}$ uma maior intensidade dessa fase. Quando o tratamento é realizado com o uso da gaiola catódica, a taxa de sputtering é maior devido à atuação do plasma em mais cátodos ocos, tendo como consequência, uma maior quantidade de átomos de ferro arrancados dos orifícios e mais intensa interação com os átomos de nitrogênio, não permitindo uma taxa difusional tão intensa no período para o interior do substrato do aço de modo que forme somente camada de difusão, aparecendo a chamada zona de compostos, como ocorreu especificamente para este aço com os parâmetros utilizados [8]. 


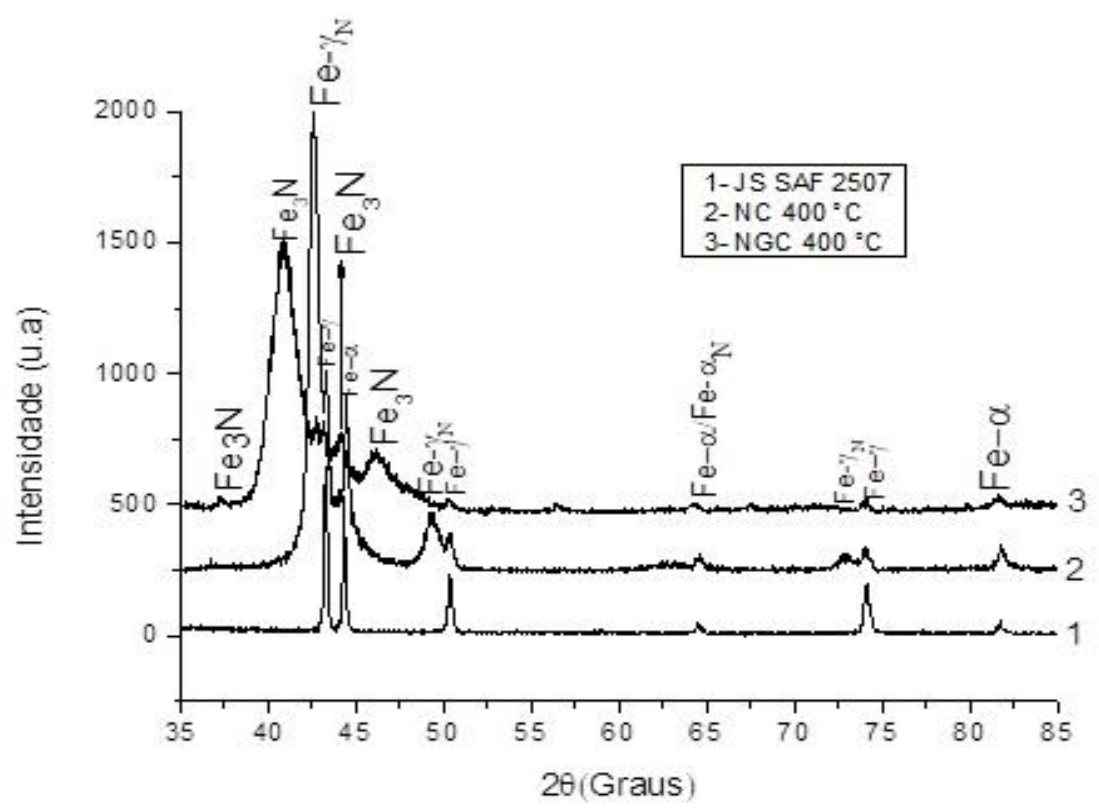

Figura 2: Padrão de difração de raio-x da junta soldada e das amostras nitretadas.

\subsection{Caracterização microestrutural}

\subsubsection{Metal base}

A análise microestrutural do material como recebido foi realizada com base na imagem mostrada na Figura 3, a qual revela uma microestrutura composta por lamelas de ferrita (fase escura) e lamelas de austenita (fase mais clara). Ambas as fases estão dispostas em grãos alongados na direção de laminação, apresentando características semelhantes aos resultados encontrados por PESSOA [10], que também desenvolveu pesquisas envolvendo o aço SAF 2507, também conhecido como UNS S32750.

Com o escopo de melhor contraste, para que fosse feita a quantificação das frações volumétricas de cada uma das fases presentes no material, realizou-se ataque químico nas amostras através de imersão das mesmas em reagente Behara. Este escureceu consideravelmente a fase ferrítica, não causando grandes alterações na austenita, resultando, portanto, em um melhor contraste que permitiu a quantificação das frações volumétricas com maior precisão. A quantificação das frações volumétricas de ferrita e austenita foi realizada através do software ImageJ. Foram analisadas cinco (05) regiões distintas sob o mesmo aumento de 200 vezes. Obteve-se, então, uma variação de fração ferrítica no metal base com um valor médio de 47,66\%. Os valores encontrados estão dentro da faixa esperada, visto que nos aços inoxidáveis super duplex (AISD), a proporção entre as fases deve ser de aproximadamente $50 \%$ - 50\% para que os mesmos apresentem as propriedades esperadas $[10,11]$.

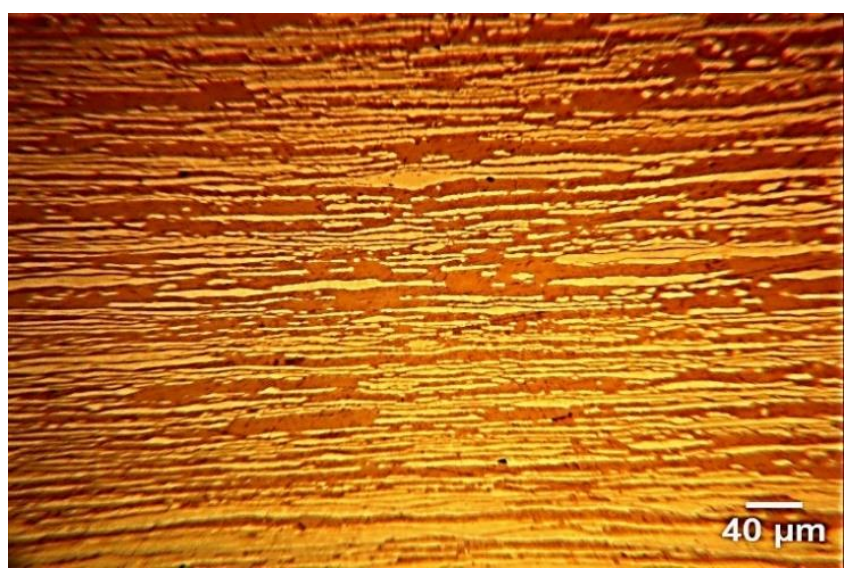

Figura 3: Microscopia ótica da microestrutura da amostra como recebida em seu estado laminado; aumento de 200x. 


\subsubsection{Junta soldada}

Antes de serem realizados os procedimentos de soldagem nas chapas do material estudado, uma série de testes foram realizados. Executou-se tal procedimento com o objetivo de se encontrar parâmetros que proporcionassem o preenchimento do chanfro, boa penetração de raiz e um reforço do cordão de solda adequado. Os testes tiveram como ponto de partida valores da norma de soldagem de aços superduplex Norsok Standard M-601 [5].

Após tais procedimentos, obteve-se um cordão com bom aspecto visual e com total preenchimento do chanfro. Houve penetração total na raiz, que também apresentou um bom aspecto visual, ou seja, uma aparência mais limpa e espelhada do que no topo, mesmo antes de ser efetuada a limpeza, o que se deu pela proteção gasosa de Ar (Argônio) puro, utilizado como gás de purga.

A zona termicamente afetada (ZTA) pôde ser facilmente identificada. Ela foi observada nas laterais da zona fundida $(\mathrm{ZF})$, adjacente às linhas de fusão, como uma região de elevado teor de ferrita e granulometria grosseira. É possível observá-la na Figura 4, onde se exibe, também, as mudanças microestruturais que acontecem na junta soldada de um aço superduplex, correlacionando-as ao diagrama de fases do sistema $\mathrm{Fe}-\mathrm{Ni}$ - $\mathrm{Cr}$ à seção de $70 \% \mathrm{Fe}$. A austenita não é estável para temperaturas acima de $1300^{\circ} \mathrm{C}$, de modo que nessas condições tendem a transformar-se em grãos ferríticos [12].

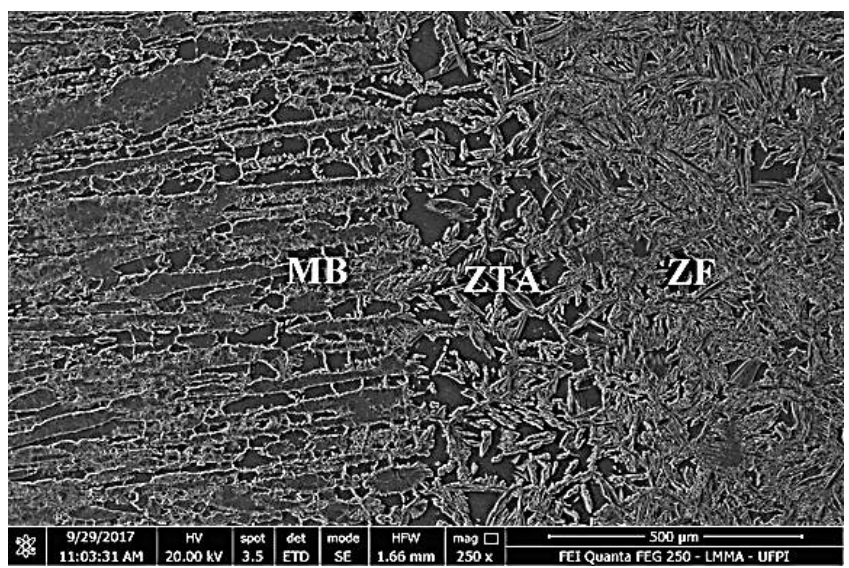

Figura 4: Microestrutura da junta soldada do aço SAF 2507; aumento de 250x.

Devido às elevadas taxas de resfriamento na região da ZTA, não há tempo suficiente para que seja promovida a transformação microestrutural da ferrita em austenita, o que resulta em uma faixa rica em grãos alfa (ferríticos). Resultados análogos foram observados por VIDEIRA [13] e PESSOA [10].

Três morfologias distintas de austenita foram observadas na ZTA com a energia de soldagem aplicada. A Figura 5 demonstra, respectivamente, estas estruturas: intragranular (no interior do grão), alotriomórfica (no contorno de grão) e de Widmanstätten (saindo do contorno de grão para o interior). Tais morfologias também foram observadas em trabalhos similares por FONSECA [14] e PESSOA [10]. AMEYAMA, et al. [15] pontuaram que a austenita Widmanstätten nucleia separadamente nas superfícies dos contornos de grão da austenita alotriomófica e cresce dentro do grão da ferrita delta com mecanismo difusional. A austenita de Widmanstätten, resultante de uma reação martensítica, pode ser benéfica, por apresentar uma microestrutura tenaz com baixo teor de carbono, além de proporcionar um alívio de tensões dependendo da temperatura de transformação. A fração volumétrica de ferrita na ZTA foi calculada com base em toda sua extensão. Para o caso da zona fundida foram utilizadas imagens do topo. A fração volumétrica de ferrita foi calculada com a mesma metodologia utilizada para o metal base e em seguida a média dos valores foi contabilizada. Os resultados obtidos foram 53,79\% para ZTA e 35,88\% para zona fundida. Os resultados corroboram com a literatura, Norsok Standard DM-601 [5], pois nos processos MIG/MAG, as frações volumétricas de ferrita tendem a serem maiores, enquanto na zona fundida, pelo uso de arame com percentual maior de Níquel, que estabiliza a austenita, tendem a ser menores.

É evidente, portanto, que a energia de soldagem possui maior efeito sobre as alterações microestruturais sofridas na ZTA quando comparadas àquelas ocorridas na zona fundida. Tal fato atribui-se às maiores temperaturas e consequentemente menores taxas de resfriamento que ocorrem na $\mathrm{ZF}$, o que resulta em maior tempo para que ocorram processos difusionais e alterações microestruturais. 


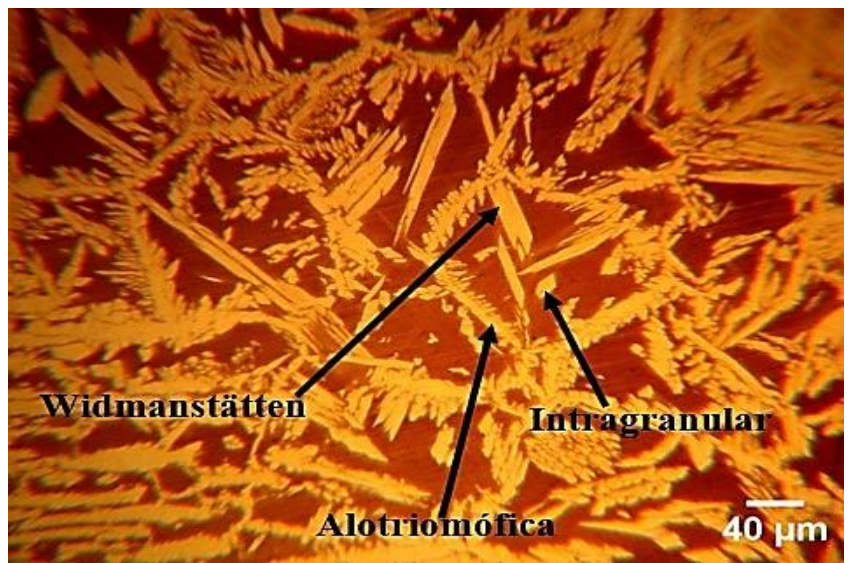

Figura 5: (a) Microscopia ótica da microestrutura da ZTA exibindo três morfologias de austenita (Alotriomórfica, Widmanstatten e Intragranular); aumento de 200x.

\subsubsection{Amostras nitretadas}

A camada nitretada após 5 horas de tratamento convencional em atmosfera gasosa contendo $20 \% \mathrm{~N}_{2}$ e $80 \%$ $\mathrm{H}_{2}$ na temperatura de $400{ }^{\circ} \mathrm{C}$ é apresentada na Figura 6 (a). Nota-se a presença de uma camada fina, contínua e de tonalidade clara.

Observa-se nos difratogramas de raio X deste aço inoxidável superduplex (Figura 2) que os planos difratados confirmam os resultados de microscopia óptica, inferindo-se que a camada nitretada produzida na temperatura de $400{ }^{\circ} \mathrm{C}$ na forma convencional possui em sua constituição elevadas contribuições de austenita expandida e ferrita expandida, não se verificando a formação de nitretos de cromo $\left(\mathrm{CrN}\right.$ e/ou $\left.\mathrm{Cr}_{2} \mathrm{~N}\right)$. A austenita expandida é proveniente da expansão volumétrica no reticulado CFC (cúbico de face centrada) da austenita $(\mathrm{Y})$ devido a sua supersaturação em nitrogênio $(\mathrm{N})$. $\mathrm{O} \mathrm{N}$ intersticial introduz grandes tensões residuais de compressão associadas a defeitos de falhas de empilhamento, o que promove o endurecimento, podendo aumentar a dureza de $4 \mathrm{GPa}$ para valores próximos de $14 \mathrm{GPa}$, sem que ocorra uma perda de resistência à corrosão. O mesmo processo difusivo ocorre com a ferrita no seu reticulado CCC (cúbico de corpo centrado), formando, assim, a ferrita expandida [1, 2].

As camadas obtidas após 5 horas de tratamento de nitretação com uso de gaiola catódica, em atmosfera gasosa contendo $80 \% \mathrm{~N}_{2}$ e $20 \% \mathrm{H}_{2}$, na temperatura de $400{ }^{\circ} \mathrm{C}$, é apresentada na Figura 6 (b). Nota-se a presença da zona de compostos (camada superior mais escura), diferentemente do tratamento convencional. Este fato está relacionado pela maior taxa de sputtering no tratamento com gaiola catódica, devido a presença de vários cátodos ocos na gaiola, como já foi relatado no difratograma desta amostra. Os resultados das espessuras médias das camadas nitretadas para as amostras $\mathrm{NC} 400{ }^{\circ} \mathrm{C}$ e $\mathrm{NGC} 400^{\circ} \mathrm{C}$ foram, respectivamente, $6,22 \pm 0,09$ e $7,63 \pm 0,07$.

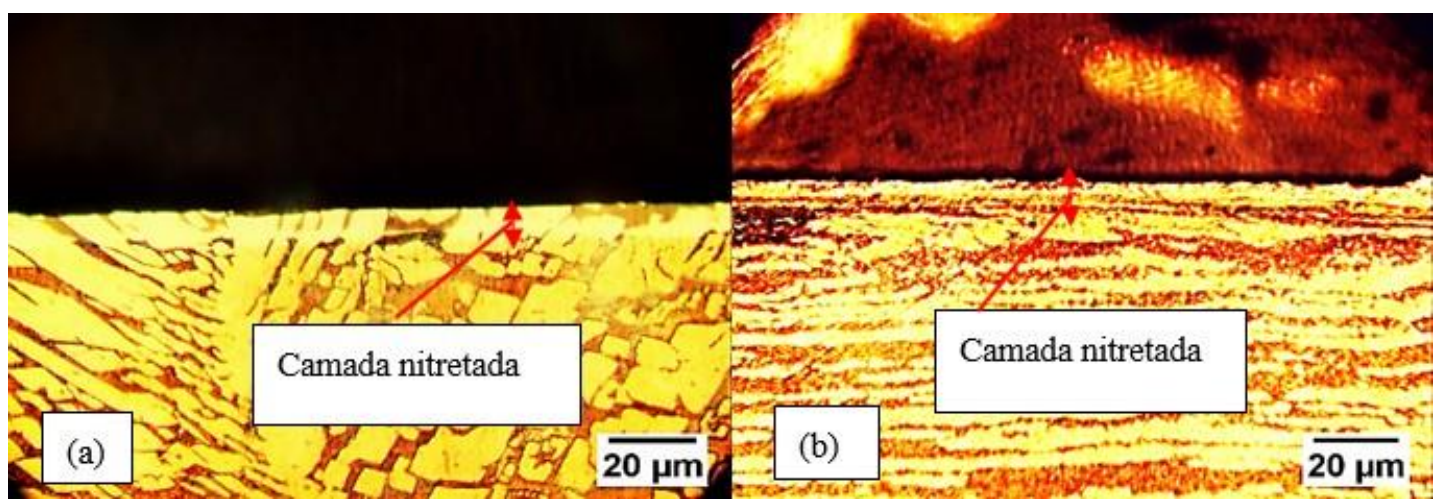

Figura 6: (a) Microscopia ótica da microestrutura de camada nitretada em plasma convencional em $400{ }^{0} \mathrm{C}$. (b) Microscopia ótica da microestrutura de camada nitretada em gaiola catódica em $400{ }^{\circ} \mathrm{C}$. 


\subsection{Ensaio de microdureza}

Para os ensaios de microdureza realizados no metal base, devido ao refinamento da microestrutura (estrutura de grãos finos), fora aplicada uma carga de 10 gf durante $15 \mathrm{~s}$. Uma carga superior não permitiria que as indentações fossem feitas inteiramente dentro dos pequenos grãos. A média de microdureza para o metal base, após dez indentações nos grãos austeníticos foi de 337 HV e nos grãos ferríticos na mesma metodologia, 374 HV. Calculando-se a média das duas fases da liga, tem-se como resultado 355,5 HV. Tal valor aproxima-se consideravelmente do valor médio para cinco medidas feitas em linha no metal base que foi igual a 310,38 HV.

Os resultados dos ensaios para o topo da solda são exibidos na Figura 7. Nesta, visualiza-se as três regiões da solda e a média das medidas em cada uma. PAULRAJ, et al. [16] obtiveram resultados onde a dureza da zona fundida se mostrou superior à do metal base. $\mathrm{O}$ comportamento foi atribuído à maior quantidade de elementos de liga empregada no metal de adição utilizado na soldagem dos AISD. A fim de favorecer a formação de austenita, o metal de adição aplicado à soldagem dos aços superduplex devem possuir teor de elementos gamagênicos (estabilizadores de austenita) superior àquele encontrado no metal base, tal fato pode ser comprovado, comparando-se as concentrações de níquel da liga soldada e do arame de solda utilizados, mostrados na Tabela 1.

Sabe-se que o metal de adição empregado é mais rico em elementos de liga que o metal base. O grande percentual de elementos de liga gamagênicos ( $\mathrm{Ni}, \mathrm{C}, \mathrm{N}$ e $\mathrm{Mn}$ ) na composição do arame de solda, além de favorecer à formação de grãos austeníticos proporciona também a melhora das propriedades mecânicas, como a microdureza, o que explica a maior média das durezas na zona fundida em relação ao metal base. Em se tratando da maior média de microdurezas na ZTA em relação às outras zonas, as impressões têm maior probabilidade de serem feitas na região da ferrita, pois é onde se encontram os maiores grãos da fase $\alpha$ e esta possui dureza mais elevada que a fase $\gamma[17]$.

$\mathrm{Na}$ Figura 7, observa-se que o tratamento com gaiola catódica em $400{ }^{\circ} \mathrm{C}$ proporcionou maiores valores na região da zona fundida e do metal de base, e que somente na região da zona termicamente afetada o tratamento convencional proporcionou maior média. Isto pode ser explicado pelos locais onde foram realizadas as indentações nesta zona. Como ela é uma região de maior presença de ferrita e pelo fato dos difratogramas deste tratamento convencional a $400{ }^{\circ} \mathrm{C}$ apresentarem planos difratados de ferrita expandida, sugerese que a maior parte das indentações foram feitas nesta fase.

Observa-se que o tratamento com gaiola apresentou maiores médias nas zonas da solda, a não ser pelo fato discutido acima sobre o ocorrido na ZTA. Esta maior média da técnica da gaiola é explicada pelo fato da maior taxa de sputtering e consequente maior deposição de $\mathrm{Fe}_{3} \mathrm{~N}$. Também foi constatado, por essa técnica (NGC), a uniformidade dos valores, ou seja, o desvio padrão apresentado foi muito baixo. É notável os maiores valores de desvio padrão das amostras tratadas em plasma convencional. No plasma convencional, há formação de anéis ao longo da amostra, tendo como consequência valores de microdureza bem distintos, como explanado por SOUSA, et al. [18]. Este observou que há um decréscimo da dureza em uma pequena área entre a borda e o centro. Isso ocorre porque os átomos ejetados por sputtering da região da borda formam uma nuvem sobre a área adjacente, dificultando a interação do plasma nessa região [8]. Para a amostra blindada com a gaiola catódica não foram observadas grandes variações de durezas, indicando a eficiência da técnica na eliminação dos efeitos de borda [19]. Na Figura 8, verifica-se maior uniformidade nas medidas de microdureza com o uso da técnica da gaiola catódica. No gráfico, tem-se as medições realizadas do centro para borda, onde se verifica maior uniformidade nos valores quando usada a gaiola catódica. Isto é corroborado pelos valores de desvio padrão das medidas de nitretação convencional e de nitretação com gaiola catódica que foram, respectivamente, $\pm 58,48$ e $\pm 17,62$. 


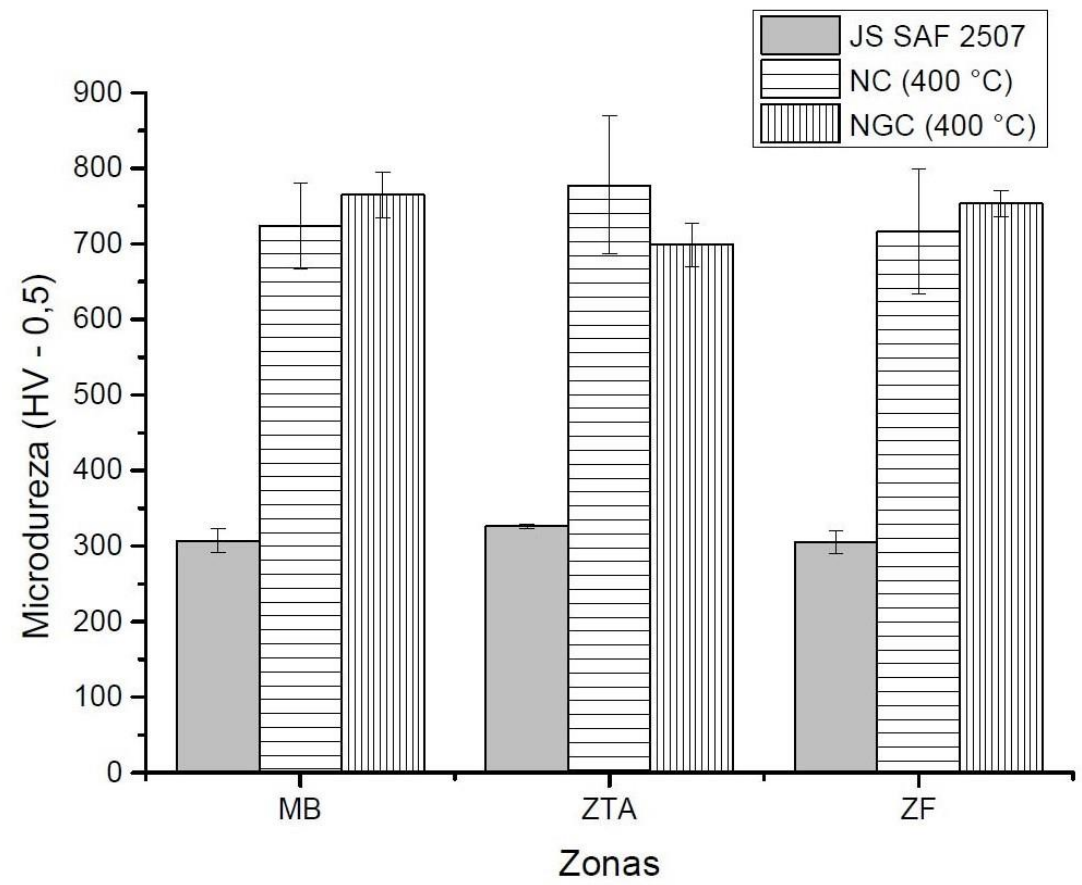

Figura 7: Microdureza média das zonas oriundas da solda sem tratamento, tratada a plasma convencional (NC) e com gaiola catódica (NGC) na temperatura de $400{ }^{\circ} \mathrm{C}$ do aço SAF 2507.

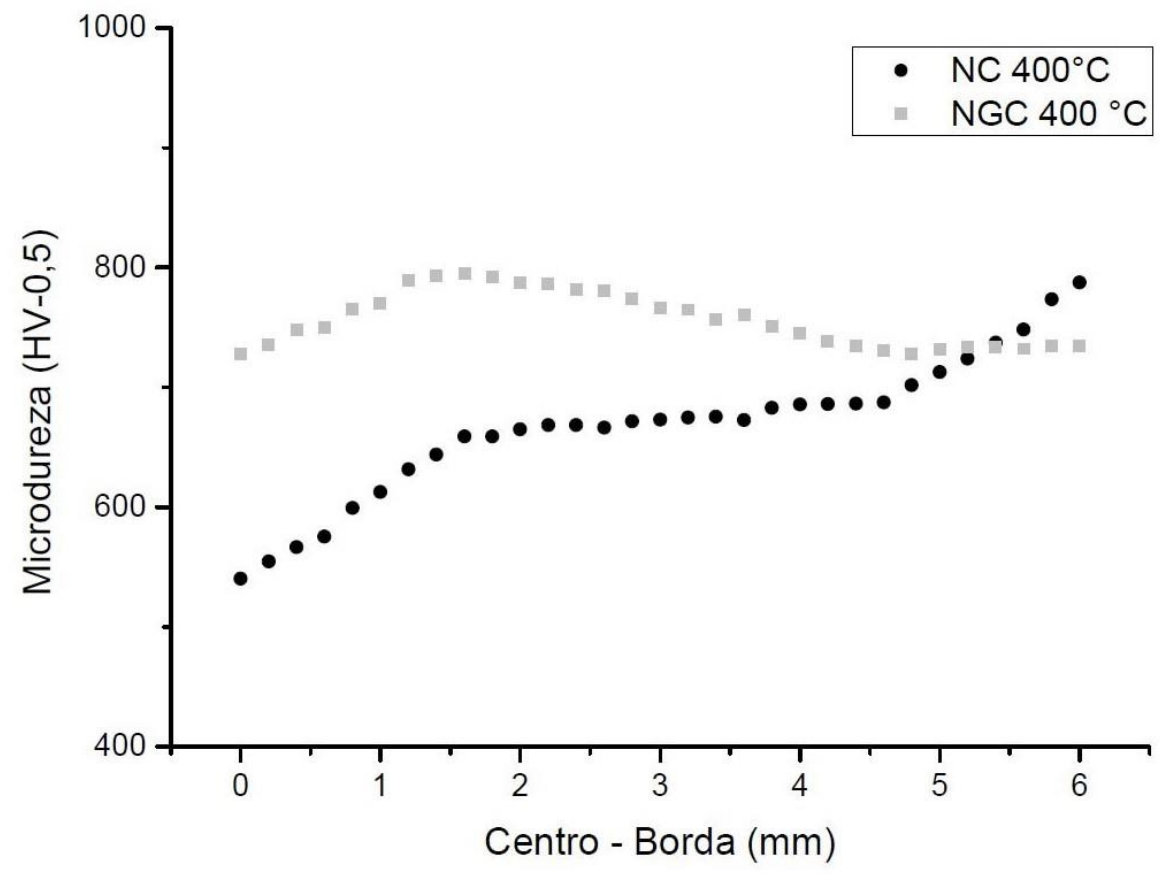

Figura 8: Microdureza do centro para borda no tratamento convencional (NC) e com gaiola catódica (NGC) na temperatura de $400^{\circ} \mathrm{C}$ do aço SAF 2507.

\section{CONCLUSÕES}

Nos resultados obtidos verificou-se que as frações volumétricas de ferrita nas zonas da solda possibilitaram valores de microdureza equivalentes ao material como recebido.

Ademais, a dureza superficial da junta soldada com a nitretação aumentou na ordem de cento e trinta e cinco por cento (135\%) em relação a junta sem tratamento, devido a maior presença das fases $\mathrm{Fe}-\gamma_{\mathrm{N}}$ (austenita expandida) e $\mathrm{Fe}-\alpha_{\mathrm{N}}$ (ferrita expandida) oriundas do tratamento convencional e da $\varepsilon-\mathrm{Fe}_{3} \mathrm{~N}$ (nitreto de ferro) 
do tratamento com gaiola catódica.

$\mathrm{E}$, finalmente, as microdurezas das amostras nitretadas em gaiola catódica exibiram maiores e mais uniformes valores que no tratamento convencional. A maior dureza é devido a maior presença de nitretos de ferro e a uniformidade é um indicativo da eliminação do efeito de bordas, defeito inerente a nitretação convencional.

\section{AGRADECIMENTOS}

Os autores agradecem ao Laboratório de Solda do curso de Engenharia Mecânica da Universidade Federal de Uberlândia e aos Laboratório de Plasma e LIMAV da Universidade Federal do Piauí.

\section{BIBLIOGRAFIA}

[1] NETO, J.O.P., SILVA, R.O., SILVA, E.H., et al., "Wear and corrosion study of plasma nitriding F53 super duplex stainless steel”, Materials Research,” v. 19, n. 6, pp. 1241-1252, 2016.

[2] PINEDO, C. E., VARELA, L. B., TSCHIPTSCHIN, A. P., "Low-temperature plasma nitriding of AISI F51 duplex stainless steel”, Surface and Coatings Technology, v. 232, pp. 839-843, 2013.

[3] LEMOS, P. A. T., SIGNORELli, R., NEVES, M. D. M. “Comparação da Junta Soldada pelo Processo GTAW dos Aços Inoxidáveis AISI 316 L e Super-Duplex UNS S32750 para Trocadores de Calor Usados em Refinarias de Petróleo", In: XXXVI Consolda - Congresso Nacional de Soldagem, Recife, Pernambuco, Brasil, 12-15 de outubro de 2010.

[4] HSIEH, R.-I., LIOU, H.-Y., PAN, Y.-T., "Effects of cooling time and alloying elements on the microstructure of the gleeble-simulated heat-affected zone of $22 \% \mathrm{Cr}$ duplex stainless steels", Journal of materials engineering and performance, v. 10, n. 5, pp. 526-536, 2001.

[5] NORSOK Standard, Welding and inspection of piping, 2004.

[6] CANDEL, E. H. P., Soldagem dos aços inoxidáveis superduplex UNS S32750 e UNS S32760, Dissertação de M.Sc., Universidade de São Paulo, Escola Politécnica da Universidade de São Paulo, São Paulo, SP, Brasil, 2016.

[7] TAVARES, S. S. M., PARDAL, J.M., LIMA, L.D., et al., "Characterization of microstructure, chemical composition, corrosion resistance and toughness of a multipass weld joint of superduplex stainless steel UNS S32750”, Materials Characterization, v. 58, n. 7, pp. 610-616, 2007.

[8] SOUSA, R. R. M., ARAÚJO, F.O., GONTIJO, L.C., et al., "Cathodic cage plasma nitriding (CCPN) of austenitic stainless steel (AISI 316): Influence of the different ratios of the $\left(\mathrm{N}_{2} / \mathrm{H}_{2}\right)$ on the nitrided layers properties”, Vacuum, v. 86, n. 12, pp. 2048-2053, 2012.

[9] CHRISTIANSEN, T., SOMERS, M. A. J., "On the crystallographic structure of S-phase", Scripta Materialia, v. 50, n. 1, pp. 35-37, Jan. 2004.

[10] PESSOA, A. R. P., Soldagem em chapas de aços inoxidáveis superduplex UNS S32750 utilizando o processo arame tubular, Tese de D.Sc., Programa de pós-graduação em engenharia e ciência de materiais, Universidade Federal do Ceará, Fortaleza, CE, 2015.

[11] GUNN, R. N., Duplex stainless steels: microstructure, properties and applications, Woodhead Publishing, 1997.

[12] MODENESI, P. J., MARQUES, P. V., BRACARENSE, A. Q., Soldagem-fundamentos e tecnologia. Editora UFMG, 2005.

[13] VIDEIRA, A.M., "Influência do aporte térmico da soldagem GTAW no balanço de fases Ferrita/Austenita do Aço Inoxidável Duplex UNS S32205”, Dissertação de M.Sc., Universidade Estadual Paulista, Faculdade de Engenharia de Ilha Solteira, Ilha Solteira, SP, 2016.

[14] FONSECA, S., "Influência do aporte térmico sobre a morfologia da austenita e na quantidade das fases em chapas soldadas de aço inoxidável duplex SAF2205”, Matéria (R.J.), v. 21, n. 1, pp. 227-234, 2016.

[15] AMEYAMA, K., WEATHERLY, G. C., AUST, K. T., "A study of grain boundary nucleated widmanstätten precipitates in a two-phase stainless steel”, Acta metallurgica et materialia, v. 40, n. 8, pp. 1835-1846, 1992. 
[16] PAUlRAJ, P., GARG, R., "Effect of Intermetallic Phases on Corrosion Behavior and Mechanical Properties of Duplex Stainless Steel and Super-Duplex Stainless Steel”, Advances in Science and Technology Research Journal, v. 9, n. 27, pp. 87-105, 2015.

[17] DABALÀ, M., CALLIARI, I., VARIOLA, A., et al., "Corrosion behavior of a superduplex stainless steel in chloride aqueous solution", Journal of materials engineering and performance, v. 13, n. 2, pp. 237240, 2004.

[18] SOUSA, R. R. M., ARAÚJO, F.O., RIBEIRO, K.J.B., et al., "Nitretação iônica em gaiola catódica do aço inoxidável martensítico AISI 420”, Matéria (R.J.), v. 13, n. 1, pp. 104-109, 2008.

[19] ALVES, C., SILVA, E.F., MARTINELLI, A.E., et al., "Effect of workpiece geometry on the uniformity of nitrided layers", Surface and Coatings Technology, v. 139, n. 1, pp. 1-5, 2001.

\section{ORCID}

Ferdinando Marco Rodrigues Borges https://orcid.org/0000-0002-0382-4254

Valdemar Silva Leal https://orcid.org/0000-0003-0199-3203

Franklyn Erikson Da Silva Guimarães https://orcid.org/0000-0002-8968-4239

Valtair Antônio Ferraresi https://orcid.org/0000-0001-7052-1555

Rômulo Ribeiro Magalhães de Sousa https://orcid.org/0000-0003-2062-6505 